\title{
A Recusa de Transfusão de Sangue por Motivos Religiosos
}

Daniel Dovigo Biziak

\begin{abstract}
RESUMO
O trabalho apresentado aborda a questão jurídica da recusa da transfusão de sangue em razão de motivos religiosos. O tema proposto, por dizer respeito à liberdade de religião e crença, é tratado na doutrina e na jurisprudência sob diversas opiniões e enfoques, de forma a enriquecer o estudo e a opinião a respeito do pretenso tema. A questão refere-se principalmente a suposta existência da colisão de direitos fundamentais, em especial o direito à vida e o direito à liberdade, o qual engloba as liberdades de crença, religião e culto. Além disso, no presente trabalho, por ter sido realizado durante o período de estudos na Universidade do Minho - Portugal, realiza-se um estudo de Direito Comparado entre a forma de que o assunto é tratado no Brasil e em Portugal.
\end{abstract}

Palavras-chave: recusa da transfusão de sangue; colisão de direitos fundamentais; direito à vida; direito à liberdade; Brasil; Portugal.

\begin{abstract}
The Refusal of Blood Transfusion because of Religious Reasons

The presented work deals with the legal issue of the refusal of blood transfusion due to religious reasons. The proposed topic, that concerns freedom of religion and belief, is treated both by the doctrine and on the jurisprudence under various opinions and approaches, which enriches the study and opinion about the pursued topic. The issue refers mainly to the supposed existence of collision of fundamental rights, specially the right to life and the right to liberty, which encompasses the freedom of belief, religion and worship. Besides that, in this present work, due to the fact that it was developed during the period of studies at the University of Minho in Portugal (Universidade do Milnho - Portugal), a comparative study of law between the way this issue is treated in Brazil and Portugal is performed.
\end{abstract}

Keywords: refusal of blood transfusion; collision of fundamental rights; right to life; right to freedom; Brazil; Portugal.

\section{Introdução}

O trabalho em questão destina-se a analisar a recusa à transfusão de sangue manifestada pelo grupo religioso denominado Testemunha de Jeová, sob o prisma dos direitos fundamentais envolvidos, mormente o direito à vida e à liberdade religiosa.

Além disso, no decorrer do trabalho, procurar-se-á realizar um estudo comparado da questão em diversos países, especialmente no Brasil e em Portugal.

Por outro lado, necessário ressaltar a complexidade e a relevância do assunto, visto que existem diversas opiniões acerca de como resolver a questão da recusa à transfusão 
sanguínea: alguns sustentam a prevalência do direito à vida, enquanto outros acreditam que a liberdade de crença e religião e a autodeterminação da pessoa humana devem sobrepor-se.

Desse modo, procurar-se-á examinar a colisão de direitos fundamentais supracitada em cada caso: paciente maior de idade consciente, com ou sem perigo de vida; paciente maior de idade inconsciente com representantes legais e portando os chamados "testamentos"; e, paciente menor de idade; elencando as soluções adotadas em cada um.

\section{Do Direito à Vida}

O direito à vida está previsto no artigo $5^{\circ}$, “caput", da Constituição da República Federativa do Brasil, sendo entendido, atualmente, não só como o direito de não ser morto por alguma pessoa (Estado ou particular), mas também a possuir uma vida digna.

Esse direito deve ser visto sob o aspecto da dignidade da pessoa humana, o qual é fundamento da República Federativa do Brasil (artigo $1^{\circ}$, III, da Constituição Federal) e representa o núcleo axiológico em torno do qual transitam todos os direitos fundamentais. Em Portugal, o direito à vida possui tratamento semelhante, com previsão no artigo $24^{\circ}$ da Constituição da República Portuguesa.

A respeito do tema, afirmam os ilustres J.J Gomes Canotilho e Vital Moreira:

$\mathrm{O}$ direito à vida está intimamente ligado a outros direitos (e princípios) como a dignidade da pessoa humana (cfr, art. $1^{\circ} \mathrm{e}$ anotações $\mathrm{V}$ a X a este preceito), desenvolvimento da personalidade (art. $\left.26^{\circ}-1\right)$, integridade física e psíquica (art. $\left.25^{\circ}-1\right)$ e igualdade (art. $\left.13^{\circ}\right) .^{1}$

Vida digna transmite a noção que a pessoa humana tem direito a uma existência que possibilite o exercício dos demais direitos da personalidade. Por essa razão, o grande mestre José Afonso da Silva leciona que a vida é a "fonte primária de todos os outros bens jurídicos".2

\footnotetext{
${ }^{1}$ CANOTILHO, José Joaquim; MOREIRA, Vital. Constituição da República Portuguesa Anotada. 4. ed. rev. Coimbra: Coimbra Editora, 2007, p. 448.

${ }^{2}$ SILVA, José Afonso da. Curso de direito constitucional positivo. 18. ed. rev. e atual nos termos da Reforma Constitucional. São Paulo: Malheiros, 2000, p. 201.
} 
No mesmo sentido encontram-se as palavras de Rodrigo César Rebello Pinho: "O direito à vida é o principal direito individual, o bem jurídico de maior relevância tutelado pela ordem constitucional, pois o exercício dos demais direitos depende de sua existência". 3

Diante disso, entende-se que o direito à vida é irrenunciável ou inviolável, ou seja, não pode ser lesado por terceira pessoa, muito menos por seu titular.

\section{Do Direito de Liberdade de Religião, de Consciência e de Crença}

\subsection{Da Liberdade}

A palavra "liberdade" deriva do latim libertas, de leber (livre), indicando genericamente a condição de livre ou estado de liberdade. Já no âmbito da ciência jurídica, é entendida como o poder outorgado ao indivíduo para que possa atuar de acordo com sua própria determinação, respeitadas, porém, as leis estabelecidas pela sociedade.

O direito de liberdade está positivado em diversas "constituições democráticas" (art. $5^{\circ}$ da Constituição Brasileira e art. $27^{\circ}$ da Constituição Portuguesa, por exemplo), garantindo a liberdade de atuação da pessoa e limite ao poder do Estado.

Nessa seara, inserem-se as liberdades de crença, consciência e religiosa.

\subsection{Da liberdade de religião, de culto e de consciência}

Em todas as sociedades a religião serviu para unir pessoas em torno de crenças, ideias e ideologias, afetando de forma incrível a forma de pensar e agir de seus seguidores.

O jurista brasileiro Manoel Gonçalves de Ferreira Filho afirma:

A religião constitui um dos mais fortes componentes das diferentes civilizações. Não é por outra razão que os estudiosos das civilizações o mais das vezes as caracterizam em função desse elemento religioso: civilização cristã; civilização muçulmana etc. ${ }^{4}$

\footnotetext{
${ }^{3}$ PINHO, Rodrigo César Rebello. Sinopse Jurídica: teoria geral da Constituição e direitos fundamentais. São Paulo: Saraiva, 2000. v. 17, p. 72.

${ }^{4}$ FERREIRA FILHO, Manoel Gonçalves. "Religião, Estado e Direito" in Revista Direito Mackenzie, São Paulo, ano 3, n. 2, jan/jun. 2002, p. 83-89.
} 
Entretanto, a liberdade de religião diferença-se da liberdade de consciência e da de culto. A respeito do tema, posicionam-se os professores J. J. Gomes Canotilho e Vital Moreira:

A liberdade de consciência consiste essencialmente na liberdade de opção, de convicções e de valores ou seja, a faculdade de escolher os próprios padrões de valoração ético e moral da conduta própria ou alheia. A liberdade de religião é a liberdade de adoptar ou não uma religião, de escolher uma determinada religião, de fazer proselitismo num sentido ou noutro, de não ser prejudicado por qualquer posição ou atitude religiosa ou anti-religiosa. A liberdade de culto é somente uma dimensão da liberdade religiosa dos crentes, compreendendo o direito individual ou coletivo de praticar atos externos de veneração próprios de uma determinada religião. ${ }^{5}$

A liberdade de religião, de consciência e de crença é um direito constitucionalmente protegido nos artigos $5^{\circ}$, VI, da Constituição Brasileira e $41^{\circ}$ da Constituição Portuguesa, sendo em ambas considerada inviolável.

Importante anotar, ainda, que a liberdade de religião está presente em diversos diplomas legais internacionais, sendo os mais destacados: Declaração Universal de 1948; Convenção Internacional sobre Direitos Civis e Políticos (1966); Declaração das Nações Unidas sobre a Eliminação de Todas as Formas de Intolerância e Discriminação com base na Religião ou Crença (1981); Documento Final de Viena (1989).

\subsection{A religião Testemunha de Jeová}

A religião Testemunha de Jeová originou-se na década de 1870, nos Estados Unidos, por meio de um grupo de estudo bíblico encabeçado por Charles Taze Russell. Atualmente, conta com mais de seis milhões de adeptos distribuídos em pelo menos 230 países.

A religião em questão, assim como as demais, possui diversos dogmas, sendo a recusa a tratamento médico com transfusão de sangue a mais conhecida e discutida juridicamente.

Álvaro da Cunha Gomes Rodrigues explica a razão pela qual as Testemunhas de Jeová recusam a transfusão sanguínea:

(...) apoiando-se numa interpretação de Genésis (9,3 a 5), Levítico $(17,10)$ e Actos $(15,20)$, os seguidores de tal credo religioso consideram que é um princípio cristão não consumir sangue, não

\footnotetext{
${ }^{5}$ CANOTILHO, José Joaquim; MOREIRA, Vital. Constituição da República Portuguesa Anotada. 4. ed. rev. Coimbra: Coimbra Editora, 2007, p. 609.
} 
havendo qualquer diferença em consumi-lo por via oral ou intravenosa. ${ }^{6}$

Corroborando a referida explicação, encontram-se os seguintes argumentos do professor brasileiro Carlos Ernani Constantino:

As denominadas Testemunhas de Jeová interpretam erroneamente a passagem bíblica de Atos, cap. 15, vers. 20, em que os Apóstolos, trazendo algumas regras do Antigo para o Novo Testamento, recomendaram aos novéis cristãos (isto é, aos recém-convertidos do Paganismo ao Cristianismo), que se abstivessem do sangue; a sobredita seita vê, aqui, uma proibição implícita da realização de transfusões sangüíneas. Entretanto, o leitor atento, lendo todo o capítulo 15 de Atos, entende que a questão posta em debate era se algumas normas do Judaísmo (Antigo Testamento) deveriam ou não prevalecer no Cristianismo (Novo Testamento); a conclusão foi a de se conservarem as regras contidas no versículo 20, entre elas, a abstenção do sangue; porém, tal proibição, oriunda do Antigo Concerto, era a de se comer o sangue dos animais (Gênesis, 9:4; Levítico, 3:17). Só dos animais, pois, naquela época, nem se sonhava com transfusões sangüíneas, entre seres humanos... As Testemunhas retrucam que o sangue humano equipara-se ao sangue dos animais, o que é uma falácia, pois a própria Bíblia diz que "a carne (natureza física) dos homens é uma e a carne dos animais é outra" (I Coríntios, 15:39). Por fim, argumentam as Testemunhas que, se não se pode comer, pela boca, o sangue, não se pode, também, ingeri-lo pela veia, em uma transfusão. Contudo, o Médico acima mencionado, Dr. Sinésio, esclarece o seguinte: "A reação metabólica é completamente diferente, ao se comer o sangue (de animais) e ao se tomar uma transfusão de sangue (humano) pela veia: quando se come o sangue (animal) - pela boca, é óbvio -, o organismo absorve as gorduras e proteínas, mas a massa sangüínea é posta fora, após a digestão, pelas fezes; quando se toma uma transfusão de sangue (humano), pela veia, a massa sangüínea aplicada não é eliminada pela digestão, mas incorpora-se no sangue do paciente". ${ }^{7}$

Em virtude disso, surge um aparente conflito de direitos fundamentais, qual seja: direito à vida versus direito de liberdade de religião e de autodeterminação.

\section{Princípios Bioéticos Envolvidos}

\subsection{Princípio da autonomia}

\footnotetext{
${ }^{6}$ RODRIGUES, Álvaro da Cunha Gomes. "Consentimento informado - pedra angular da responsabilidade criminal do médico" in Direito da Medicina - I, Coimbra: Coimbra Editora, v. 6, setembro 2002, p. 43.

${ }^{7}$ CONSTANTINO, Carlos Ernani. "Réplicas às críticas tecidas ao nosso artigo Transfusão de sangue e omissão de socorro" in Apostila de Direito Penal II, Franca, p. 69-70.
} 
Princípio da autonomia ou autodeterminação diz respeito à possibilidade da pessoa humana decidir sobre o tratamento ou procedimento médico a ser aplicado, levando em consideração seus valores íntimos.

\subsection{Princípio do consentimento informado}

Diretamente ligado ao princípio da autonomia encontra-se o princípio do consentimento informado, o qual aduz que antes de uma intervenção médica, o médico deve informar sobre os riscos e benefícios das terapias cabíveis ao caso, deixando o paciente escolher a de seu interesse.

O consentimento informado, considerado, na maioria dos casos, como pré-requisito das intervenções médicas, é descrito por João Álvaro Dias:

(...) como um diálogo entre o doente e o médico em que ambas as partes trocam informações e se interrogam reciprocamente; diálogo que há-de culminar na concordância ou anuência do doente à realização de certo tratamento ou intervenção. ${ }^{8}$

\subsubsection{Requisitos de validade do consentimento}

São requisitos do consentimento do paciente: a) o seu esclarecimento, nos termos do artigo $157^{\circ}$ do Código Penal Português ${ }^{9}$; b) liberdade e seriedade do consentimento; c) atualidade do consentimento, sendo revogável até o momento da realização do procedimento médico; d) capacidade da pessoa, que será o limite etário de 14 anos (artigo $38^{\circ}, n^{\circ} 3$, do Código Penal Português), e discernimento necessário para avaliar o seu sentido e alcance no momento em que o presta.

\subsection{Princípio da beneficência}

\footnotetext{
${ }^{8}$ DIAS, João Álvaro, apud RODRIGUES, Álvaro da Cunha Gomes. "Consentimento informado - pedra angular da responsabilidade criminal do médico" in Direito da Medicina - I, Coimbra: Coimbra Editora, v. 6, setembro 2002 , p. 35.

9 “Artigo $157^{\circ}$

Dever de esclarecimento

Para efeito do disposto no artigo anterior, o consentimento só é eficaz quando o paciente tiver sido devidamente esclarecido sobre o diagnóstico e a índole, alcance, envergadura e possíveis consequências da intervenção ou do tratamento, salvo se isso implicar a comunicação de circunstâncias que, a serem conhecidas pelo paciente, poriam em perigo a sua vida ou seriam susceptíveis de lhe causar grave dano à saúde, física ou psíquica”.
} 
De forma didática, Jeovanna Viana Alves conceitua, assim, o princípio da beneficência:

\begin{abstract}
A beneficência é definida como a obrigação de garantir o bem-estar do indivíduo e a obrigação de desenvolver meios para tornar mais fácil, no futuro, dar esta garantia. Este princípio está expresso no Juramento de Hipócrates, afirmando que o médico deve actuar visando o melhor interesse para o seu paciente. ${ }^{10}$
\end{abstract}

Na relação existente entre médico e seu paciente, o princípio da beneficência é de observância obrigatória, visto que o profissional tentará sempre utilizar os meios mais eficazes para não agravar o mal do paciente e curá-lo da forma mais rápida e menos dolorosa.

A maior crítica que se faz ao princípio em questão é o risco de paternalismo, quando o médico poderia agir completamente desvinculado do interesse e da vontade do paciente.

\title{
4 Colisão de Direitos Fundamentais
}

No caso das transfusões de sangue em pessoas Testemunhas de Jeová ocorre uma colisão entre o direito à vida e o direito de religião ou crença. Entretanto, deve-se buscar a harmonização entre esses direitos, através de uma ponderação de valores de acordo com cada caso concreto, utilizando-se, sobretudo, do princípio da proporcionalidade ou razoabilidade.

\subsection{O caso dos maiores de idade}

\subsubsection{No Brasil}

A situação da recusa da transfusão de sangue por motivos religiosos está, no Brasil, longe de ser resolvida, existindo argumentos e decisões dos tribunais em todos os sentidos. Vejamos, então, quais são os argumentos predominantes.

a) Se o paciente estiver no pleno gozo de suas faculdades mentais, em condições de manifestar de forma válida suas convicções religiosas, ele possuirá o direito de decidir sobre qualquer forma de intervenção em seu próprio corpo, da mesma forma que desejou ir até o

${ }^{10}$ ALVES, Jeovanna Viana. Ensaios Clínicos, Coimbra: Coimbra Editora, v. 8, julho 2003, p. 61-62. 
hospital ou clínica médica. Nesse caso, pode-se dizer que predomina o princípio bioético da autonomia.

Nessa direção, encontra-se o artigo 15 do Código Civil Brasileiro de 2002: "Art. 15. Ninguém pode ser constrangido a submeter-se, com risco de vida, a tratamento médico ou a intervenção cirúrgica".

b) Por outro lado, quando o paciente está em perigo iminente de vida, o médico pode e deve realizar a transfusão de sangue, mesmo contra a vontade do doente. A referida conduta é admitida pelo Código Penal Brasileiro, em seu artigo art. 146, $\S 3^{\circ}$, I:

Art. 146. Constranger alguém, mediante violência ou grave ameaça, ou depois de lhe haver reduzido, por qualquer outro meio, a capacidade de resistência, a não fazer o que a lei permite, ou a fazer o que ela não manda:

(...)

$3^{\circ}$ Não se compreendem na disposição deste artigo:

I - a intervenção médica ou cirúrgica, sem o consentimento do paciente ou de seu representante legal, se justificada por iminente perigo de vida;

II - a coação exercida para impedir suicídio.

Corroborando a importância da vida, o Código Penal Brasileiro disciplina o tipo penal da omissão de socorro, o qual coloca a existência humana sob a responsabilidade de qualquer pessoa que a possa salvar:

Art. 135. Deixar de prestar assistência, quando possível fazê-lo sem risco pessoal, à criança abandonada ou extraviada, ou à pessoa inválida ou ferida, ao desamparo e em grave e iminente perigo; ou não pedir nesses casos, o socorro da autoridade pública.

(...)

Parágrafo único. A pena é aumentada de metade, se a omissão resulta lesão corporal de natureza grave, e triplicada se resulta a morte.

Na mesma direção, encontram os seguintes artigos do Novo Código de Ética Médica Brasileiro (Resolução CFM n 1.931 , de 17 de setembro de 2009) que tratam das vedações aos médicos:

Art. 22. Deixar de obter consentimento do paciente ou de seu representante legal após esclarecê-lo sobre o procedimento a ser realizado, salvo em caso de risco iminente de morte.

Art. 31. Desrespeitar o direito do paciente ou de seu representante legal de decidir livremente sobre a execução de práticas diagnósticas ou terapêuticas, salvo em caso de iminente risco de morte.

Na França, assim como no Brasil, há o predomínio de decisões no sentido da preservação da vida, contrariando a vontade manifestada pelo paciente. 
c) Caso o doente esteja inconsciente e seus parentes ou representantes legais manifestarem o desinteresse pela transfusão de sangue, o médico deverá realizá-la, contrariando a vontade destes.

d) No caso do paciente apresentar-se inconsciente e sem acompanhamento, mas portar um documento que o identifica como membro da seita Testemunha de Jeová, o médico deve contrariar a vontade presumível, desconsiderando o referido documento.

É importante ressaltar que, em todos os casos, a transfusão de sangue só pode ser realizada contra a vontade do paciente se os demais métodos cirúrgicos não tiverem cabimento ou não solucionarem a situação de risco atual e iminente. Assim, antes da transfusão, é imprescindível a tentativa de solução do caso com tratamentos alternativos.

\subsubsection{Em Portugal}

a) No caso do paciente estar consciente e manifestar o seu desinteresse pela transfusão sanguínea, o problema resolver-se-á da mesma maneira que no Brasil, isto é, será observada a vontade do doente.

A respeito da necessidade de consentimento eficaz, encontra-se a seguinte lição do respeitado Manuel da Costa Andrade: “Toda a intervenção médico-cirúrgica preenche a factualidade típica do crime de Ofensas Corporais, só podendo a respectiva ilicitude ser excluída mediante consentimento eficaz". ${ }^{11}$

b) Por outro lado, o entendimento predominante difere do Brasil no que tange ao paciente em iminente perigo de vida, visto que a grande maioria dos juristas sustenta o respeito pela decisão manifestada pelo paciente, ainda que este esteja correndo perigo de vida. Assim, pode-se falar na prevalência do princípio bioético da autonomia, bem como dos princípios constitucionais da autodeterminação e inviolabilidade da integridade física e moral.

Nessa seara, situa-se o Parecer no 46/CNECV/2005 do Conselho Nacional de Ética para as Ciências da Vida, o qual recomenda aos profissionais de saúde o respeito pela decisão manifestada pelo paciente, desde que emitida pelo próprio, com capacidade para decidir, de forma expressa e livre.

\footnotetext{
${ }^{11}$ ANDRADE, Manuel da Costa, apud RODRIGUES, Álvaro da Cunha Gomes. "Consentimento informado pedra angular da responsabilidade criminal do médico" in Direito da Medicina - I, Coimbra: Coimbra Editora, v. 6, setembro 2002, p. 11.
} 
Importante notar que essa posição, prevalência do princípio da autonomia, também é adotada pela Espanha e Estada Unidos.

c) No caso do doente estar inconsciente, mas seus familiares ou amigos demonstrarem ser ele Testemunha de Jeová, o médico poderá realizar a transfusão, baseando, para isso, na falta de atualidade e veracidade do dissentimento do paciente e no princípio de "favor vitae et salutis".

d) Quando o paciente estiver inconsciente e sem acompanhamento, mas portar um documento declarando o seu desejo pela não transfusão sanguínea, o médico poderá realizar a transfusão sanguínea. Entende-se que estes "testamentos" são dotados de reduzido valor, sendo considerados, apenas, como indícios para a presunção do dissentimento, visto que falta a eles o requisito da atualidade do consentimento.

\section{2. $O$ caso dos menores de idade}

\subsubsection{No Brasil}

Quase unânime é a questão da recusa dos genitores dos pacientes menores quanto à realização das transfusões de sangue em seus filhos: a grande maioria dos operadores do direito defende a implementação da transfusão de sangue, em desfavor da oposição manifestada pelos pais, considerando tal decisão como abuso do poder familiar. Desse modo, a vida do menor deve ser sempre preservada, tendo o médico que obter do Poder Judiciário a autorização para a realização da operação.

Até mesmo nos Estados Unidos, onde predominam as decisões a favor do princípio da autonomia, prevalece a idéia de suprimento do consentimento pelas autoridades judiciárias.

Sustentando tal tese, Paulo Sergio Leite Fernandes aduz:

Nos Estados Unidos, hoje, baseiam-se os Tribunais, para outorga de tal autorização, no conceito de que o tratamento médico é necessidade básica da vida. Na medida em que o Estado tem atribuição para garantir à criança a satisfação das necessidades básicas, e sendo os cuidados médicos de fundamental necessidade, conclui-se que o juiz pode determinar que o menor seja tratado. ${ }^{12}$

\footnotetext{
12 FERNANDES, Paulo Sergio Leite, apud TOKARSKI, Mariane Cristine. "Liberdade e Vida: a recusa à transfusão de sangue à luz dos direitos fundamentais". Jus Navigandi, Teresina, ano 10, n. 891, 11 dez. 2005. Seção Doutrina. Disponível em: <http://jus2.uol.com.br/doutrina/texto.asp?id=7711>. Acesso em: 01 abr. 2009.
} 
Há doutrinadores brasileiros, ainda, que realizam uma diferenciação entre os menores, considerando os maiores de 16 anos de idade como maiores amadurecidos (em razão dos direitos que lhe são assegurados por lei), e os adolescentes entre 12 anos completos e 16 anos incompletos como maiores amadurecidos de acordo com o seu grau de maturidade psicossocial. Para isso, tomam por base os artigos 12 da Convenção das Nações Unidas sobre os Direitos das Crianças, adotada em 20.11.1989, e $2^{\circ}$ da Lei n. ${ }^{\circ} 8.069 / 90$ (Estatuto da Criança e do Adolescente).

\subsubsection{Em Portugal}

Tomando como base o artigo $38^{\circ}$ do Código Penal Português, deve-se analisar separadamente o caso dos menores e maiores de 14 anos de idade.

No caso do doente ser pessoa menor de 14 anos de idade e houver a recusa dos pais à transfusão de sangue, predomina a ideia de que a vida e a saúde do menor devem ser levadas em conta, devendo a referida recusa ser suprimida pelos competentes meios legais.

No sentido dessa solução encontra-se o artigo $1918^{\circ}$ do Código Civil Português:

\footnotetext{
Quando a segurança, a saúde, a formação moral ou a educação de um menor se encontrem em perigo e não seja caso de inibição do exercício do poder paternal, pode o tribunal, a requerimento do Ministério Público ou de qualquer das pessoas indicadas no $\mathrm{n}^{\circ} 1$ do artigo $1915^{\circ}$, decretar as providências adequadas (...).
}

Por outro lado, se o médico não dispuser, em razão da gravidade do caso, de tempo hábil para pedir autorização judicial, ele deve realizar a transfusão contra a vontade dos pais, baseando, para isso, no Parecer da Procuradoria-Geral da República de 16 de janeiro de 1992.

Urge analisar agora a situação dos maiores de 14 anos de idade.

Em virtude da Convenção dos Direitos da Criança e do Código Penal Português pregarem que o consentimento expresso por maiores de 14 anos com discernimento necessário para avaliar o seu sentido e alcance no momento em que é prestado ser válido e eficaz, entendia-se que a sua decisão a respeito da transfusão tinha que ser respeitada.

Entretanto, o Conselho Nacional de Ética para as Ciências da Vida, no seu Parecer $n^{\circ}$ 46, afirmou serem os menores equiparados aos interditos e portadores de anomalia psíquica, estando eles, assim, incapazes de tomar decisões sobre cuidados de saúde. 
Tentando solucionar esse problema de normas que se contradizem, posicionam-se Rita Fonseca Marques e Patrícia Trindade Gonçalves:

\begin{abstract}
Assim, e numa tentativa de integrar as diversas disposições legais e normativas, consideramos que actualmente, o médico que seja confrontado com a recusa de transfusão sanguínea por parte de um menor de pelo menos 14 anos, deve optar pelo recurso aos tribunais para desta forma conseguir autorização para a transfusão, ou a confirmação da validade plena da vontade expressa pelo menor. ${ }^{13}$
\end{abstract}

\title{
CONCLUSÃO
}

Diante do exposto, percebe-se que a questão de recusa de transfusão sanguínea pelas Testemunhas de Jeová é altamente controvertida, tendo que ser analisada de acordo com cada caso concreto.

Examinando as diversas situações elencadas, observa-se que algumas possuem soluções semelhantes no Brasil e em Portugal - no caso dos maiores: a) conscientes, sem estarem em perigo iminente de vida; c) inconscientes acompanhados por parentes e representantes legais; d) inconscientes portadores de "testamentos"; e no caso dos menores necessitados da transfusão sanguínea, recusada por seus representantes legais.

Importante ressaltar, ainda, que as soluções descritas são as predominantes e não as únicas existentes, razão pela qual se verifica a dificuldade e importância do tema.

Em virtude da previsão dos direitos em conflito na constituição, é necessário aplicar o princípio da proporcionalidade/razoabilidade, buscando sempre a máxima efetivação dos direitos fundamentais em cada caso concreto.

Por derradeiro, tendo em vista o crescente processo de globalização, o qual atinge todas as esferas, até mesmo as do conhecimento e das ideias, verifica-se que o Brasil tende a dar predominância ao princípio bioético da autonomia ou autodeterminação em todos os casos, até mesmo quando o paciente estiver consciente, mas em iminente perigo de vida. Assim, o Brasil passaria a adotar a mesma posição de Portugal, Espanha e Estados Unidos.

\section{REFERÊNCIAS BIBLIOGRÁFICAS}

ALVES, Jeovanna Viana. Ensaios Clínicos, Coimbra: Coimbra Editora, v. 8, julho 2003.

${ }^{13}$ MARQUES, Rita Fonseca; GONÇALVES, Patrícia Trindade. “A recusa de transfusão: da prática à Jurisprudência", in Sub Judice, n 38, 2007, p. 97. 
CANOTILHO, José Joaquim; MOREIRA, Vital. Constituição da República Portuguesa Anotada. 4. ed. rev. Coimbra: Coimbra Editora, 2007.

CONSTANTINO, Carlos Ernani. "Réplicas às críticas tecidas ao nosso artigo Transfusão de sangue e omissão de socorro". Apostila de Direito Penal II, Franca.

FERREIRA FILHO, Manoel Gonçalves. "Religião, Estado e Direito" in Revista Direito Mackenzie, São Paulo, ano 3, n. 2, jan/jun. 2002.

MARQUES, Rita Fonseca; GONÇALVES, Patrícia Trindade. "A recusa de transfusão: da prática à Jurisprudência”, in Sub Judice, n 38, 2007.

PINHO, Rodrigo César Rebello. Sinopse Jurídica: teoria geral da Constituição e direitos fundamentais. São Paulo: Saraiva, 2000. v. 17.

RODRIGUES, Álvaro da Cunha Gomes. "Consentimento informado - pedra angular da responsabilidade criminal do médico" in Direito da Medicina - I, Coimbra: Coimbra Editora, v. 6, setembro 2002 .

SILVA, José Afonso da. Curso de direito constitucional positivo. 18. ed. rev. e atual nos termos da Reforma Constitucional. São Paulo: Malheiros, 2000.

TOKARSKI, Mariane Cristine. "Liberdade e Vida: a recusa à transfusão de sangue à luz dos direitos fundamentais". Jus Navigandi, Teresina, ano 10, n. 891, 11 dez. 2005. Seção Doutrina. Disponível em: < http://jus2.uol.com.br/doutrina/texto.asp?id=7711 >. Acesso em: 01 de abril 2009. 